\title{
Design, rationale, and baseline characteristics of a cluster randomized controlled trial of pay for performance for hypertension treatment: study protocol
}

\author{
Laura A Petersen ${ }^{1 *}$, Tracy Urech ${ }^{1}$, Kate Simpson ${ }^{1}$, Kenneth Pietz ${ }^{1}$, Sylvia J Hysong ${ }^{1}$, Jochen Profit ${ }^{1}$, \\ Douglas Conrad ${ }^{2}$, R Adams Dudley ${ }^{3}$, Meghan Z Lutschg ${ }^{1}$, Robert Petzel ${ }^{4}$ and LeChauncy D Woodard ${ }^{1}$
}

\begin{abstract}
Background: Despite compelling evidence of the benefits of treatment and well-accepted guidelines for treatment, hypertension is controlled in less than one-half of United States citizens.

Methods/design: This randomized controlled trial tests whether explicit financial incentives promote the translation of guideline-recommended care for hypertension into clinical practice and improve blood pressure (BP) control in the primary care setting. Using constrained randomization, we assigned 12 Veterans Affairs hospital outpatient clinics to four study arms: physician-level incentive; group-level incentive; combination of physician and group incentives; and no incentives (control). All participants at the hospital (cluster) were assigned to the same study arm. We enrolled 83 fulltime primary care physicians and 42 non-physician personnel. The intervention consisted of an educational session about guideline-recommended care for hypertension, five audit and feedback reports, and five disbursements of incentive payments. Incentive payments rewarded participants for chart-documented use of guideline-recommended antihypertensive medications, BP control, and appropriate responses to uncontrolled BP during a prior four-month performance period over the 20-month intervention. To identify potential unintended consequences of the incentives, the study team interviewed study participants, as well as non-participant primary care personnel and leadership at study sites. Chart reviews included data collection on quality measures not related to hypertension. To evaluate the persistence of the effect of the incentives, the study design includes a washout period.
\end{abstract}

Discussion: We briefly describe the rationale for the interventions being studied, as well as the major design choices. Rigorous research designs such as the one described here are necessary to determine whether performance-based payment arrangements such as financial incentives result in meaningful quality improvements.

Trial Registration: http://www.clinicaltrials.govNCT00302718

\section{Background}

Despite compelling evidence of the benefits of treatment, hypertension is controlled in less than one-half of United States (US) citizens with the disease [1]. Inadequate blood pressure (BP) control results in excess morbidity and mortality from cardiac, renal, and peripheral

\footnotetext{
* Correspondence: laurap@bcm.tmc.edu

${ }^{1}$ Health Policy and Quality Program, Michael E. DeBakey VA Medical Center Health Services Research and Development Center of Excellence, and Section for Health Services Research, Department of Medicine, Baylor College of Medicine, Houston, TX, USA

Full list of author information is available at the end of the article
}

vascular disease [2]. While some cases of poor BP control relate to patients' compliance with treatment, there is significant under-treatment of hypertension on the part of physicians. In one study, hypertension patients received less than $65 \%$ of care that was indicated for this condition [3].

Under-treatment of hypertension is puzzling, because good evidence exists about the efficacy of antihypertensive medications. Despite widespread dissemination of guidelines for treatment of hypertension (including the Seventh Report of the Joint National Committee (JNC

\section{C) Biomed Central}


7) on Prevention, Detection, Evaluation, and Treatment of High Blood Pressure), and widespread comparative effectiveness trials such as the Antihypertensive and Lipid-Lowering Treatment to Prevent Heart Attack Trial (ALLHAT) [4], translation into clinical practice has been incomplete [5].

Awareness of barriers to such clinical research translation has raised enthusiasm about using novel methods, such as financial incentives, to overcome them [6]. A number of pay-for-performance programs have been implemented in the United Kingdom (UK) and the US $[7,8]$. However, research evidence of effectiveness of pay-for-performance programs, particularly randomized trials, is limited $[9,10]$. Using a cluster randomized controlled trial (RCT), we are testing the effect of explicit financial incentives to promote the translation of guideline-recommend care for hypertension into clinical practice and thereby improve BP control in the primary care setting. This trial addresses the needs of policy makers, payers, physicians, administrators, and others for information about a clinically relevant intervention in routine practice. We are not aware of other ongoing randomized trials of pay for performance directed at physicians and provider groups [11].

\section{Design of trial}

Because our goal was to evaluate the impact of financial incentives on individual physicians as well as primary care provider groups, we implemented a cluster randomized controlled design and clustered at the facility level [12].

\section{Design of incentives}

Should individuals, groups, or some combination receive financial incentives for their performance? One could anticipate that with group- or practice-team-level incentives, individual physicians would not capture the full returns on their individual effort to improve the quality of their care. Traditional economic theory suggests that the potential for some physicians to 'free-ride' on the efforts of others may lead many to reduce their individual efforts [10,13]. Conversely, the problem with rewarding individuals, but not the individual's team or group, is that cooperation among the group is not necessarily encouraged. Moreover, group incentives may be important in supporting and rewarding infrastructure improvements to the healthcare delivery system. Studies evaluating the chronic care model suggest that multidisciplinary teams produce better patient outcomes $[14,15]$. Yet, traditional fee-for-service payment models create disincentives for making organizational changes in care delivery $[15,16]$. Thus, theory suggests the potential for group-level incentives to support organizational and team-based efforts to improve quality, but it is not yet known how these effects compare to individual-level incentives.

The design of incentives for quality also raises the question, what should we reward? Would incentives targeting processes (i.e., what clinicians do) or outcomes ( $i$. $e$., what ultimately happens to patients) be expected to produce the highest quality? Of course, the best process-of-care measures are those for which there is evidence that better performance leads to better outcomes. But it is important to note that process-of-care measures may be more sensitive to quality differences than are measures of outcomes, because a poor outcome does not necessarily occur every time there is a quality problem. Furthermore, outcomes are often dependent upon events that are outside of the control of the clinician. For example, one can prescribe guideline-recommended medications, but if the patient is not able to adhere to these medications, the BP may not be controlled. One theoretical problem with using incentives solely based upon process-of-care measures is that physicians may attempt 'gaming' and focus solely on the measure (i.e., use of a guideline-recommended medication), while ignoring the intended outcome, which is the attainment of a target BP.

To avoid the problems associated with the exclusive use of process-of-care or outcome measures described above and to dampen the gaming incentive, both a process-of-care measure (use of guideline-recommended medications in patients who have no other compelling indications) and an intermediate outcome measure (achievement of the JNC 7 BP goal) will be used. This approach may avoid the pitfalls of process-of-care measures alone that can encourage gaming, while avoiding the disadvantage of basing incentives solely on outcomes that may be relatively rare or difficult to achieve and somewhat beyond the control of the provider. Thus, a combined approach potentially capitalizes upon the advantages and complementary nature of both types of quality-of-care measures [9]. The design of our trial reflects the following logic: other things being equal, process-based incentives will create stronger incentives for improvement in process (which the physician can directly control); similarly, process-based incentives may also produce better outcomes (assuming that the processes being incentivized improve outcomes). We believe that combining outcome-based with processbased incentives has the potential to produce even greater quality improvement than process measures alone [17].

A third design question is whether the incentive payments should be distributed according to relative performance (i.e., the participant's percentile ranking compared to peers) or absolute performance (i.e., strictly according to performance relative to the same 
standard)? The former approach may be problematic because participants cannot directly control the behavior or outcomes of others on whom a relative comparison is based. The latter approach rewards behavior that the individual or group can directly control $[10,13]$. Therefore, we designed our incentives to reward participants each time they provided guideline-recommended medications and/or their patient met the guideline-recommended BP threshold or, in the absence of controlled $\mathrm{BP}$, the participant appropriately responded to uncontrolled BP [17].

In this article, we describe the methods used to assess the effects of physician- and group-level financial incentives on processes and outcomes of care for outpatients with hypertension.

\section{Methods/design Study objectives}

The goals of this study were to: determine the effect of physician-level financial incentives on processes and outcomes of care for outpatients with hypertension; assess the impact of group-level financial incentives; ascertain whether there are additive effects of physicianplus group-level financial incentives; evaluate the persistence of the effect of financial incentives; and identify any unintended consequences of these explicit financial incentives.

\section{Study design}

This study is a four-arm cluster RCT of individual physician incentives, group-level financial incentives, and performance audit and feedback to improve the translation of guideline-recommended care for hypertension in the primary care setting. Participants at study sites randomized to one of the three intervention arms earned either physician-level, group-level, or physician- and group-level incentives (combined incentive arm). Both intervention and control arm (no incentives) participants received audit and feedback reports.

\section{Study sites and constrained randomization}

We partnered with five Veterans Affairs (VA) regional networks to implement the study. Within these networks, hospital-based VA outpatient clinics that could conduct human subjects' research and had eight or more eligible primary care physicians were potential study sites. Of the 22 potential study sites, only 12 met the requirements for study implementation: hospital director approval; Institutional Review Board (IRB) and VA Research and Development (R\&D) approval; having a credentialed individual willing to serve as the site's PI; and having at least five consented physician participants at time of randomization. We stratified these 12 study sites on the following characteristics expected $a$ priori to be associated with responses to financial incentives and the study outcomes of interest: teaching status, geographic location, participation in the ALLHAT study [4] (a very large trial of various medications used to treat hypertension in both VA and non-VA settings that included intensive education regarding hypertension control and use of evidence-based hypertension treatment at participating sites), and the degree of clinic geographic proximity within the primary care setting at each study site. We identified a hospital as a teaching facility if it was listed in the Association of American Medical College's (AAMC) Council of Teaching Hospitals $(\mathrm{COTH})$ directory or if the American Medical Association's (AMA) Fellowship and Residency Electronic Interactive Database (FREIDA) listed the VA facility as having a 'major' affiliation with a medical school. To determine geographic region, we used US Census Bureau information to identify the corresponding Census Division for each site. Study site investigators provided clinic layout information, and we designated sites as being integrated if the layout was amenable to group cohesion (e.g., the primary care clinic offices were located on the same floor at the study site).

We randomized at the cluster (facility) level. To ensure that facilities of the same type would not be concentrated in the same arm, we employed the following constraints: all non-teaching facilities could not be in the same arm; all non-ALLHAT sites could not be in the same study arm; no arm could have two sites from the same geographic location; and at least two sites per arm had to meet the criteria for geographic integration (Figure 1). Using SAS version 9.1.3 (SAS Institute Inc, Cary, NC), a data analyst on the study team who was not involved in the processes of site selection or subject recruitment assigned a uniform random number to each of the possible allocations and selected the allocation sequence with the highest random number. Table 1 lists the characteristics of the study sites.

\section{Power and sample size}

The anticipated effect sizes were based upon a systematic review of financial incentives in healthcare [9]. In that review, the range of increases in performance using physician-level incentives was $5.9 \%$ to $25.3 \%$, most of which were for preventive services such as immunizations. Because this study assesses treatment of a chronic disease requiring multiple types of interventions (i.e., medications, counseling, monitoring, lifestyle modification), rather than a single immunization, the increase in performance is anticipated to be somewhat less than those trials at the high end of this range.

The sample size calculation must take into account several factors. First, this is a cluster design, randomized at the facility level. Second, there is a measurement 


\begin{tabular}{|c|c|c|c|}
\hline \multirow[b]{2}{*}{$\downarrow$} & \multicolumn{2}{|c|}{$\begin{array}{l}\text { 12 VA hospitals randomized to } \\
1 \text { of the } 4 \text { study arms } \\
\text { Randomization constrained by: } \\
\text { - Hospital teaching status } \\
\text { - Geographic location } \\
\text { - ALLHAT study site } \\
\text { - Primary care geographic integration }\end{array}$} & \multirow[b]{2}{*}{$\downarrow$} \\
\hline & \multicolumn{2}{|l|}{$\frac{1}{1}$} & \\
\hline $\begin{array}{l}\text { Physician Incentive } \\
\text { Audit/Feedback }\end{array}$ & $\begin{array}{l}\text { Group Incentive } \\
\text { Audit/Feedback }\end{array}$ & $\begin{array}{c}\text { Physician and Group } \\
\text { Incentives } \\
\text { Audit/Feedback }\end{array}$ & $\begin{array}{c}\text { No incentive } \\
\text { Audit/Feedback }\end{array}$ \\
\hline 3 hospitals & 3 hospitals & 3 hospitals & 3 hospitals \\
\hline $\begin{array}{l}\text { Physician } \\
\text { participants* }\end{array}$ & $\begin{array}{c}\text { Physician participants } \\
\text { Non-physician } \\
\text { participants } †\end{array}$ & $\begin{array}{c}\text { Physician participants } \\
\text { Non-physician } \\
\text { participants }\end{array}$ & Physician participants \\
\hline $\begin{array}{l}\text { gure } 1 \text { Randomization sch } \\
\text { dministration. *Enrolled up to } \\
\text { narmacists) at each study site. }\end{array}$ & $\begin{array}{l}\text { ALLHAT = Antihypertensive } \\
\text { orimary care physicians at eac }\end{array}$ & $\begin{array}{l}\text { pid-Lowering Treatment to Pre } \\
\text { site. +Enrolled up to } 15 \text { non-p }\end{array}$ & $\begin{array}{l}\text { Heart Attack Trial; VA = Veteran } \\
\text { an participants (e.g., nurses and }\end{array}$ \\
\hline
\end{tabular}

error associated with estimating each physician's proportion, because we can only sample a finite number of patients per physician. Finally, there must be a correction for multiple comparisons because we are testing two effects and an interaction. The sample size computation uses the non-central t-distribution and is based on a $\mathrm{SAS}^{\circledR}$ program from Donner and Klar [18]. An iterative solution is required because the number of degrees of freedom depends on the sample size. The variance in measurements is the sum of the variance between hospitals, the remaining variation between physicians and the error variance of the measurement.

Table 1 Study site characteristics

\begin{tabular}{|c|c|c|c|c|c|}
\hline VA hospital & City, State & $\begin{array}{l}\text { Teaching } \\
\text { facility* }\end{array}$ & $\begin{array}{l}\text { US Census } \\
\text { Division }\end{array}$ & $\begin{array}{l}\text { ALLHAT study } \\
\text { site }\end{array}$ & $\begin{array}{l}\text { Primary care geographic } \\
\text { integrationt }\end{array}$ \\
\hline VA Boston HCS & Boston, MA & $x$ & New England & & $X$ \\
\hline Providence VAMC & Providence, RI & $x$ & New England & $x$ & $x$ \\
\hline VA Connecticut HCS & Newington, CT & & New England & & $x$ \\
\hline Charlie Norwood VAMC & Augusta, GA & $x$ & South Atlantic & $x$ & $X$ \\
\hline Ralph H. Johnson VAMC & Charleston, SC & $x$ & South Atlantic & $x$ & $x$ \\
\hline Birmingham VAMC & Birmingham, AL & $x$ & E. South Central & & $x$ \\
\hline Aleda E. Lutz VAMC & Saginaw, Ml & & E. North Central & & \\
\hline John D. Dingell VAMC & Detroit, MI & $x$ & E. North Central & $x$ & $x$ \\
\hline $\begin{array}{l}\text { G.V. (Sonny) Montgomery } \\
\text { VAMC }\end{array}$ & Jackson, MS & $x$ & E. South Central & $x$ & \\
\hline Michael E. DeBakey VAMC & Houston, TX & $x$ & W. South Central & $x$ & \\
\hline Oklahoma City VAMC & $\begin{array}{l}\text { Oklahoma City, } \\
\text { OK }\end{array}$ & $x$ & W. South Central & $x$ & $x$ \\
\hline Minneapolis VAMC & Minneapolis, MN & $x$ & W. North Central & $x$ & \\
\hline
\end{tabular}

ALLHAT = Antihypertensive and Lipid-Lowering Treatment to Prevent Heart Attack Trial; HCS = healthcare system; US = United States;

VA $=$ Veterans Administration; VAMC = Veterans Affairs Medical Center

*Designated as a teaching facility if the facility was either listed in the Association of American Medical College's (AAMC) Council of Teaching Hospitals (COTH) directory or if the American Medical Association's (AMA) Fellowship and Residency Electronic Interactive Database (FREIDA) database listed the VA facility as having a 'major' affiliation with a medical school.

tDesignated as geographically integrated if the primary care clinic layout was amenable to group cohesion (e.g., the primary care clinic offices located on the same floor at the study site). 
Estimates of the variance between hospitals and the variance between physicians were obtained from pilot data. The error variance of measurement of the physician's proportion was calculated from the binomial distribution. Using these data, we estimated values of the intraclass correlation of 0.39 for appropriate medication and 0.14 for BP control.

We provide power calculations for the process and outcome measures. We calculated effect sizes for various values of the difference in percentage use of appropriate medication and BP control we could detect between the study arms with $80 \%$ power using a two-sided t-test with $95 \%$ significance. Greater increases in power result from increasing the number of clusters than by increasing the number of cases within clusters [18]. However, it is much more difficult and costly to recruit more hospitals. We chose to use three hospitals per study arm with five physicians per hospital and 40 patient charts per physician. We determined that we could detect a difference of 17 percentage points between the mean proportions of appropriate medications in the arms, for an effect size of 1.59. Similarly, for BP control, we determined we could detect a difference of 15 percentage points between the mean proportions in the study arms for an effect size of 1.30 .

We adjusted the sample size to account for anticipated physician participant attrition. Using VA physician workforce planning data, we estimated $5.8 \%$ would leave VA employment during the study. We adjusted our initial sample size, five physicians per site, to seven per site to account for attrition using the formula proposed by Lachin [19], defined as $1 /(1-R)^{2}$ where $R$ is the dropout rate.

\section{Baseline characteristics of study participants}

Primary care physicians who worked at least 0.6 fulltime equivalents (approximately three days per week related to clinical activities) or had a panel size of at least 500 patients were eligible to participate. Research assistants on the Houston coordinating center study team obtained informed consent from at least five eligible participants (see Power and sample size section) at each study site prior to randomization. We sought to avoid coercion by informing the individuals that participation was strictly voluntary, that their decision to participate would not impact their employment status, and that their supervisors and other hospital officials would not have access to their performance data. Following randomization of study sites to study arms, we continued to consent eligible physician participants as necessary to meet our recruitment goal of seven physicians per site (see Power and sample size section). We enrolled a total of 83 physicians from 12 VA hospitals. At two sites, more than seven eligible physicians consented for the study, so we randomly chose seven among those who consented.

All enrolled physicians in a hospital were placed in the same study arm. At the six study sites randomized to the group-level incentive, the physicians invited up to 15 non-physician colleagues, either other clinicians (e.g., nurses and pharmacists) or administrative support staff (e.g., clerks) or both, to participate. Research assistants on the Houston coordinating center study team obtained informed consent from 42 non-physician participants. Table 2 lists the demographic characteristics of the physician and non-physician primary care personnel who were enrolled at the start of the intervention period.

\section{Interventions \\ Provider education}

Between February and April 2008, we provided all participants with the current JNC 7 hypertension guidelines during live educational webinars presented by a cardiologist and an internist. At the sessions, participants learned their study arm assignment. Participants in the intervention arms received information about the magnitude and criteria for the incentives.

\section{Audit and feedback}

All participants (including the control group) received an audit and feedback report via a secure, password-protected study website following the end of each of five data collection periods, approximately four months apart. Reports were designed to contain features, which in previous research had improved the effectiveness of feedback in healthcare settings [20,21]. Reports included data reflecting individual and group scores, earnings for the study period, total earnings to date, and future performance goals. Each time we posted the feedback report for a particular period to the website, we emailed study participants to announce its availability. Figure 2 shows the layout of the audit and feedback report for a physician participant in the combined incentive arm.

\section{Financial incentives}

The financial incentive intervention phase of the study started in April 2008 and consisted of disbursements of incentive payments earned over each of five performance periods. For each performance period, trained chart abstractors extracted relevant data from the VA electronic medical records of 40 randomly selected patients in each physician's panel who met eligibility criteria. Only those patients with hypertension who had a face-to-face healthcare encounter where hypertension could be addressed during the performance interval were eligible for inclusion in the sampling frame. For the first performance period, we examined a four-month period prior to the start of the incentive intervention phase to assess participants' baseline performance. We 
Table 2 Characteristics of physicians and non-physician primary care personnel enrolled at the start of the intervention

\begin{tabular}{|c|c|c|}
\hline Characteristic* & Primary care physicians $(n=83)$ & $\begin{array}{l}\text { Non-physician personnel } \\
(n=42)\end{array}$ \\
\hline Male, n (\%) & $45(54.2)$ & $6(14.3)$ \\
\hline Age at start of study, mean (SD), y & $46.5(7.8)$ & $48.7(8.7)$ \\
\hline \multicolumn{3}{|l|}{ Race/ethnicity, n (\%) } \\
\hline White & $35(42.2)$ & $24(57.1)$ \\
\hline Black & $6(7.2)$ & $12(28.6)$ \\
\hline Asian & $34(41.0)$ & $3(7.1)$ \\
\hline Hispanic & $4(4.8)$ & $1(2.4)$ \\
\hline Othert & $3(3.6)$ & $2(4.8)$ \\
\hline Unknown‡ & $1(1.2)$ & 0 \\
\hline Board certified, n (\%) & $76(91.6)$ & N/A \\
\hline Primary specialty internal medicine, $\mathrm{n}(\%)$ & $71(85.5)$ & N/A \\
\hline Trained in a subspecialty/secondary specialty, n (\%) & $18(21.7)$ & $\mathrm{N} / \mathrm{A}$ \\
\hline Years practicing since residency completion, mean (SD) & $12.6(7.8)$ & N/A \\
\hline Proportion of professional time spent delivering patient care, mean (SD) & $0.89(0.13)$ & $0.86(0.20)$ \\
\hline Role in patient care delivery, $\mathrm{n}(\%)$ & N/A & \\
\hline Licensed practical nurse & N/A & $10(23.8)$ \\
\hline Medical support assistant & N/A & $3(7.1)$ \\
\hline Pharmacist & N/A & $2(4.8)$ \\
\hline Physician assistant or nurse practitioner & N/A & $5(11.9)$ \\
\hline Registered nurse & N/A & $16(38.1)$ \\
\hline Registered nurse case manager or care coordinator & N/A & $6(14.3)$ \\
\hline
\end{tabular}

*Data collected as part of the participant demographic questionnaire conducted following the informed consent discussion.

tOther includes participants that described themselves as Native Hawaiian/Other Pacific Islander, American Indian/Alaska Native, or belonging to more than one race/ethnicity group.

$\ddagger$ Participant declined to answer.

anchored performance periods two to five from the start of the incentive intervention phase. Incentive payments arrived in participants' VA paychecks approximately every four months and typically followed the posting of the feedback report for that performance period. After each data collection period, we notified participants via e-mail the date of the paycheck in which the payment was to appear.

\section{Study outcomes}

We rewarded participants for delivering guideline-concordant care for management of hypertension. Incentive earnings for each four-month performance period were based on the proportion of the physician's sampled patients meeting either or both performance measures: receiving guideline-recommended antihypertensive medications; and achieving the guideline-recommended BP threshold OR having an appropriate response to uncontrolled BP (Figure 3). According to the guideline in place at the time of the study, thiazide diuretics should be used either alone or in combination with other classes of medications to control BP in most patients with uncomplicated hypertension. In patients with compelling indications for the use of other antihypertensive drug classes (e.g., diabetes mellitus or renal disease), medications appropriate for those highrisk conditions should be used as initial therapy for controlling BP [2]. JNC 7 guidelines recommend treating BP to a goal of $<140 / 90 \mathrm{~mm} \mathrm{Hg}$ in most patients. In those with hypertension and co-existing diabetes mellitus and/or renal disease, the goal was $<130 / 80 \mathrm{~mm} \mathrm{Hg}$. Examples of appropriate responses to uncontrolled BP included increasing the dosage of a guideline-recommended antihypertensive medication or recommending a lifestyle modification, such as the Dietary Approaches to Stop Hypertension (DASH) eating plan to a patient with Stage 1 hypertension.

\section{Incentive payment structure}

The five participating VA Networks' contributions to the incentive fund totalled $\$ 250,000$. Based on this amount, we then simulated study results using pilot data and estimated rates of improvement to determine the greatest per-outcome incentive that we could provide per physician. The results indicated a per-patient maximum amount of $\$ 18.20$, one-half from use of guideline-recommended medications and one-half from either BP control or appropriate response to uncontrolled BP. 


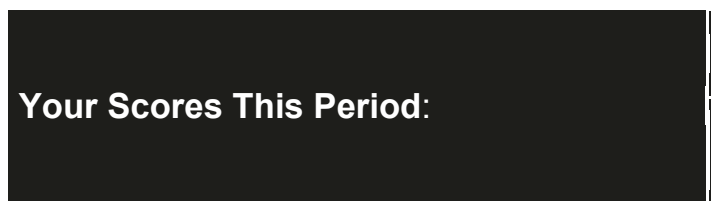

Number of eligible hypertensive patients randomly sampled from your panel/group

Number of patients who received guidelinerecommended BP medications

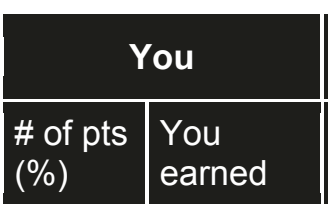

40

$\begin{array}{rrr}36 & \$ 327.60 & 201 \\ (90 \%) & \$ 1,829.10\end{array}$

\section{Your group}

\# of pts Group

(\%)

Congratulations! You are among the top 10\% of performers across the entire study for this period.

$\begin{array}{lrrrr}\text { Number of patients with controlled BP } & 28 & \$ 254.80 & 198 & \$ 1,801.80\end{array}$

Number of patients with uncontrolled BP...

... who received an appropriate clinical response to uncontrolled $\mathrm{BP}$ this period

$\begin{array}{rrr}5 & \$ 45 \\ (42 \%) & \$ 45.50 & (49 \%)\end{array}$

\section{Total Earnings:}

This period - Congratulations! Good work!

Overall

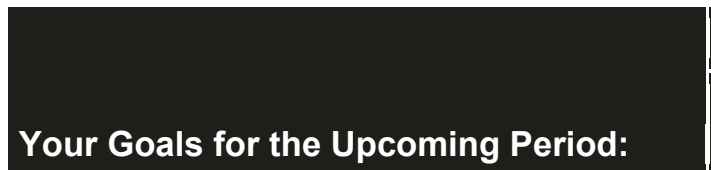

\begin{tabular}{|c|}
\hline \multicolumn{2}{|c|}{ You } \\
\hline $\begin{array}{c}\% \text { of } \\
\text { pts. }\end{array}$ \\
\hline
\end{tabular}

\section{Your group}

$\%$ of pts.

Percent of eligible hypertensive patients in your panel/group...

... who will receive guidelinerecommended BP medications

$90 \%$

$85 \%$

For the next period, your goal is to maintain or exceed your current performance level. Keep up the great work!

... with controlled BP

$85 \%$

$85 \%$

... with uncontrolled $\mathrm{BP}$ who will receive an appropriate clinical response to

$83 \%$

$83 \%$ uncontrolled BP

If you and your group meet or exceed your goals next period, you and your group could earn at least:

\section{Total earnings that you will receive this period:}

\section{$\$ 862.89$}

Figure 2 Feedback report \#3 for a physician participant in the individual and group incentives study arm. BP $=$ blood pressure.

Table 3 describes the intervention components and estimated incentive payouts for the study arms. For the physician-level incentive arm, each physician's reward reflected the number of successful outcomes achieved among the 40 randomly chosen patients. The group incentive earnings were based on the aggregated performance of the physicians. We allowed participants at the six group sites to choose how to allocate the group 


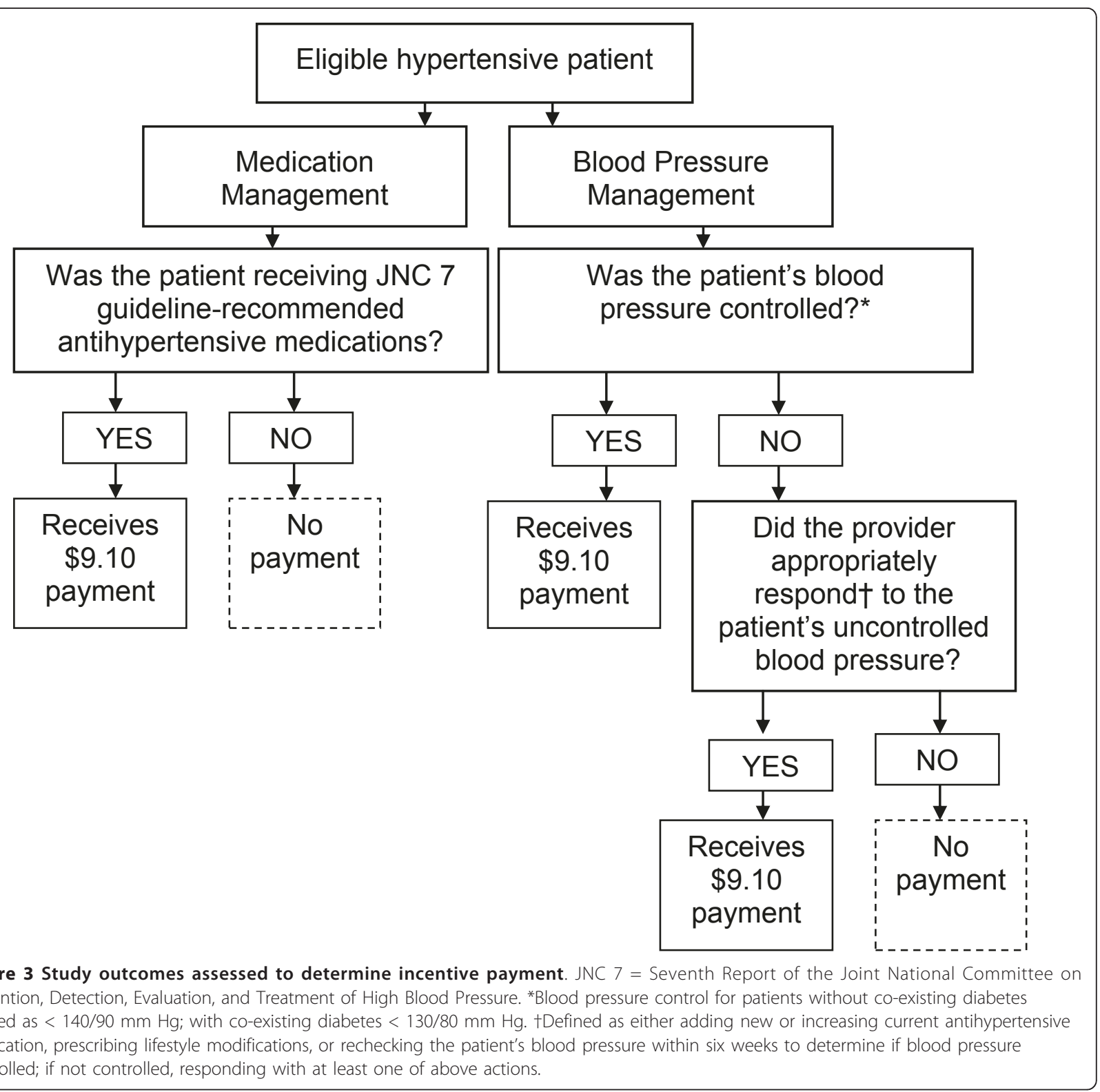

earnings (e.g., divide earnings among themselves as personal income or use them to provide patient education materials or other supplies for the clinic). Each group chose to divide the earnings evenly amongst themselves. For the combined incentive arm, the physicians received a payment that included their individual performance earnings as well as their share of the group's aggregated performance reward. Non-physician participants received their share of the group's aggregated performance reward.

\section{Data collection}

We developed a data abstraction tool and electronically collected data on the physicians' patients from the VA
Computerized Patient Records System (CPRS). Abstractors at the Houston coordinating center collected data on patient demographics, vital signs, diabetes mellitus, cardiovascular conditions, renal conditions, terminal illness, and other relevant co-morbidities, laboratory values and medications, including dosages, allergies, contraindications, and patient refusals for all study sites. Additionally, we collected lifestyle modifications recommended by the provider or other medical staff members and information on study outcomes addressed at followup visits within a given timeframe. We collected hemoglobin A1c (HbA1c) levels in patients with diabetes, low-density lipoprotein cholesterol (LDL-C) levels in patients with hyperlipidemia, and colorectal cancer 
Table 3 Intervention components and incentive payouts

\begin{tabular}{|c|c|c|c|c|c|c|c|c|c|}
\hline \multirow[b]{2}{*}{ Study Arm } & \multicolumn{3}{|c|}{ Intervention components } & \multicolumn{2}{|c|}{ Participants } & \multirow[b]{2}{*}{$\begin{array}{l}\text { Performance } \\
\text { evaluated }\end{array}$} & \multirow[b]{2}{*}{$\begin{array}{l}\text { Per outcome per patient } \\
\text { incentive award }\end{array}$} & \multicolumn{2}{|c|}{$\begin{array}{l}\text { Total estimated } \\
\text { incentive over entire } \\
\text { study period }\end{array}$} \\
\hline & $\begin{array}{l}\text { Audit/ } \\
\text { feedback } \\
\text { report }\end{array}$ & $\begin{array}{l}\text { Individual } \\
\text { physician } \\
\text { incentive }\end{array}$ & $\begin{array}{l}\text { Group } \\
\text { incentive }\end{array}$ & Physicians & $\begin{array}{c}\text { Non- } \\
\text { physicians }\end{array}$ & & & $\begin{array}{l}\text { Individual } \\
\text { Physician }\end{array}$ & Group \\
\hline $\begin{array}{l}\text { Physician } \\
\text { incentive }\end{array}$ & $\cdot$ & $\cdot$ & & $\cdot$ & & Physician & $\$ 9.10$ & $\$ 2681$ & N/A \\
\hline $\begin{array}{l}\text { Group } \\
\text { incentive }\end{array}$ & $\cdot$ & & $\cdot$ & $\cdot$ & $\cdot$ & Physician & $\$ 9.10$ & N/A & $\$ 17206$ \\
\hline $\begin{array}{l}\text { Physician and } \\
\text { group } \\
\text { incentives }\end{array}$ & $\cdot$ & $\cdot$ & $\cdot$ & $\cdot$ & . & Physician & $\$ 9.10$ & $\$ 2696$ & $\$ 18872$ \\
\hline $\begin{array}{l}\text { No incentives } \\
\text { (control) }\end{array}$ & $\cdot$ & & & $\cdot$ & & Physician & $\$ 9.10$ & N/A & N/A \\
\hline
\end{tabular}

*Estimates based on outcome rates from pilot study and projected improvement rates per period as follows: individual arm - 0.05 for process measures (guideline-recommendation medication and appropriate response) and 0.03 for blood pressure control; group arm - 0.02 for process measures and 0.01 for blood pressure control; combined arm - 0.06 for process measures and 0.04 for blood pressure control.

tFor a group that includes seven physicians. Group incentive award determined by summing the incentive amounts earned by all seven physicians in the group.

screening procedures among eligible patients to assess unintended consequences, i.e., neglect of these conditions or missed screening opportunities, that may have resulted from the intervention's focus on hypertension care.

After a training session, chart abstractors were required to complete 20 practice charts with $95 \%$ agreement on key data elements with all other abstractors and the trainer. During each period of data collection, the abstraction manager spot-checked charts for accuracy in abstracting key variables, addressing problem areas with abstracters as necessary. At the end of each period of data collection, we randomly selected at least three charts from each site in order to evaluate abstracter agreement. Also, we blinded chart abstractors to the study's objectives and to study arm assignments to ensure impartiality in the data collection process.

\section{Interviews - team planning, pay-for-performance} perspectives, and unintended consequences of incentives After participants received their second incentive payments and audit and feedback reports, the study team, including an industrial/organizational psychologist, interviewed 17 physician participants and 11 non-physician participants across the study sites to collect data about the strategies that they used to improve hypertension care, including clinic planning and team interaction shared mental models. Twelve physician participants and four non-physicians also completed a similar interview after the fourth disbursement of incentive payments and audit and feedback reports. These distinct interviews were intended to provide insights on how care strategies and planning may have evolved over time, and the drivers behind any observed changes.
Following the posting of the participants' final audit and feedback reports in April 2010, we interviewed 28 physicians and 10 non-physician participants across the study sites to ascertain their perspectives on financial incentives, the intervention's impact on team dynamics and care delivery for hypertension and non-related conditions, and organizational changes that occurred at the study site during the intervention period. Focusing on similar concept domains, we also interviewed primary care personnel, 24 physicians and 25 non-physicians across the sites, who did not participate in the intervention and primary care leadership at the 12 sites.

\section{Washout period and post-washout period data collection}

The four-month post-washout performance period began 12 months following the posting of the final audit and feedback report to the study's website. To evaluate the persistence of the intervention, we will subsequently collect the same data that were collected during the intervention. A timeline of the study's activities, from physician recruitment to post-washout data collection, is presented in Figure 4.

\section{Data analysis}

The unit of analysis will be the physician. We will perform a repeated measures longitudinal analysis using mixed models to evaluate the effect of the intervention. We will evaluate three different predictors for each outcome: each incentive arm versus the control arm; individual-level incentive arms versus arms with no individual incentives; and group-level incentive arms versus arms with no group incentives. Models will be developed independently for each outcome. First, using scientifically relevant covariates selected $a$ priori, we will construct a maximal model for each outcome as described 
by Cheng et al. [22]. The maximal model provides the flexibility to evaluate both the covariance structure and the list of covariates for inclusion in the final model. The relationship between each continuous covariate and the outcome will be explored to assess the need for covariate transformations. We also will determine whether any site-to-site variation exists and include the facility (cluster) as a random effect as necessary. We then will perform backward elimination to delete variables of no value, arriving at our final model.

\section{Discussion}

In this paper, we describe our rationale, methods, and baseline participant characteristics for a cluster-randomized trial to assess the effectiveness of pay for performance in improving hypertension control and use of guideline-recommended medications in the primary care setting. The potential impact of this study is great.
Seventy-two million Americans have hypertension [23], but hypertension is controlled in less than one-half of those who carry this diagnosis [1]. A variety of methods, such as audit and feedback, academic detailing, reminders, guidelines, and combinations of interventions have not succeeded in eliminating the under-treatment of hypertension [24]. Given the track record of other interventions, the effectiveness and cost-effectiveness of financial incentives in overcoming such barriers to translation of research into practice must be rigorously evaluated [25].

Other studies of the use of financial incentives for improving healthcare quality have suffered from a dilution of the incentive due to multiple payers or competing incentives that make it difficult to assess effectiveness $[9,26]$. Relative to these situations, studying incentives in the VA healthcare system provides several advantages. First, the VA is both the insurer and the 
provider, so organizational responses to incentives are easier to anticipate and assess. Second, the VA uses a single payment approach, rather than a diverse mix as seen elsewhere. The VA employs salaried physicians to care for its enrollees. The VA healthcare system consists of 21 networks that operate on a global budget appropriated by Congress. Funding is distributed to the networks via a form of capitation in which payments are made per veteran meeting eligibility criteria [27]. The VA has a common national electronic medical information system, making the collection of common practice data across widely disparate geographic sites and types of facilities feasible. Thus, carrying out the study in the VA allows an evaluation of the effectiveness of financial incentives that is free from some of the limitations encountered in other settings.

Paying more for healthcare services shown to improve quality could have a tremendous impact on care delivery. However, despite great potential, numerous questions are unanswered. How effective (and cost-effective) are financial incentives for quality? Can we expect the effect of financial incentives to persist after they are stopped? Will important patient care activities that are not rewarded financially be neglected? Thus, despite enthusiasm about the potential for aligning financial incentives with high quality healthcare, there are a number of fundamental unanswered questions about their optimal design, effectiveness, and implementation that we will address in this trial [9].

While our study design has numerous strengths, we must acknowledge some limitations. First, as part of the VA Healthcare Personnel Enhancement Act of 2004 (implemented in 2006) [28], the VA healthcare system instituted a new payment system that includes performance pay based on the accomplishment of specific clinical quality goals and objectives which may be established at the local, network, or national level. However, although this program provides financial incentives for improvements in quality of care, the specific measures (i.e., hypertension control, diabetes management, colorectal cancer screening) for which payments are given have not been implemented uniformly across VA facilities. In addition, VA performance pay encompasses a wide array of measures, while our incentive focuses solely on management of hypertension, thus maximizing the effect of our intervention. Further, by using a RCT design, we limit the likelihood of confounding by other concurrent quality improvement programs. Second, the VA has an extensive system of clinical reminders (i.e., use of thiazide diuretics in patients with hypertension or use of aspirin in patients with ischemic heart disease) designed to promote the provision of guideline-recommended care. However, while the VA has implemented a variety of quality improvement strategies, our pilot data indicate that there remains room for further improvement. Third, although the VA healthcare system cares for few women patients, the subjects of this study are physicians. There is little reason to believe that the effect of a financial incentive to a physician would result in different treatment of a woman or a man with hypertension. Thus, findings from this study will be relatively generalizable to budgeted systems and staff-model health maintenance organizations (HMOs) that serve many millions of patients, to Centers for Medicare and Medicaid Services (CMS) with 40.5 million beneficiaries, and indirectly applicable to other healthcare delivery models. Finally, it is possible that there may be a 'volunteer effect' among participants. For example, physicians with a bias toward use of financial incentives may have been more likely to participate in our study. However, we expect that the randomized control design of our study will limit the effect of this potential source of bias.

In this paper, we have given a brief description of the rationale for the interventions being studied in this trial of pay for performance, as well as some of the design choices. Rigorous research designs such as this one are necessary to determine whether performance-based payment arrangements result in meaningful quality improvements. In this large cluster-RCT of pay for performance, we are seeking to provide such evidence for one of the most common chronic conditions affecting US citizens.

\section{Acknowledgements}

We gratefully acknowledge the VA Network Directors who provided the financial incentives for this study as well as the VA staff who participated. This work is supported in part by Veterans Affairs Health Services Research \& Development (HSR\&D) Investigator-Initiated Research (IIR) 04349 (PI Laura A. Petersen, MD, MPH), NIH RO1 HL079173-01 (PI Laura A. Petersen, MD, MPH), the American Recovery and Reinvestment Act of 2010 (NHLBI 1R01HL079173-S2), and the Houston VA HSR\&D Center of Excellence HFP90-020 (PI Laura A. Petersen, MD, MPH). Dr. Petersen was a recipient of the American Heart Association Established Investigator Award (Grant number 0540043N) and was a Robert Wood Johnson Foundation Generalist Physician Faculty Scholar (Grant number 045444) at the time that this study was planned and funded. Dr. Hysong was a recipient of an NHLBI Investigator Research Supplement to Promote Diversity in Health-Related Research (1R01HL079173-S1) during the early stages of the study and is currently a VA HSR\&D Career Development Awardee (CDA 07-0181). Dr. Profit's contribution is supported in part by the Eunice Kennedy Shriver National Institute of Child Health and Human Development \#1 K23 HD056298-01 (PI: Jochen Profit, MD, MPH). Dr. Conrad is an awardee of the Robert Wood Johnson Foundation Health Care Financing and Organization Program (Grant number 63214). Dr. Dudley is a Robert Wood Johnson Investigator Awardee in Health Policy. The views expressed are solely of the authors, and do not necessarily represent those of the $\mathrm{VA}$.

\section{Author details}

${ }^{1}$ Health Policy and Quality Program, Michael E. DeBakey VA Medical Center Health Services Research and Development Center of Excellence, and Section for Health Services Research, Department of Medicine, Baylor College of Medicine, Houston, TX, USA. ${ }^{2}$ University of Washington, Magnuson Health Sciences Center, Seattle, WA, USA. ${ }^{3}$ Department of Health Services, Institute for Health Policy Studies, University of California, San 
Francisco, San Francisco, CA, USA. ${ }^{4}$ Under Secretary for Health, Department of Veterans Affairs, Washington, D.C., USA.

\section{Authors' contributions}

LAP conceived of the study, obtained funding, supervised the research team, and drafted the manuscript. All authors participated in designing the study. TU, KS, KP, MZL, and LDW helped to draft the manuscript. SJH, JP, DC, and RAD provided critical revision of the manuscript for important intellectual content. All authors approved the final version of the manuscript.

\section{Competing interests}

The authors declare that they have no competing interests.

Received: 29 July 2011 Accepted: 3 October 2011

Published: 3 October 2011

\section{References}

1. Wang TJ, Vasan RS: Epidemiology of uncontrolled hypertension in the United States. Circulation 2005, 112:1651-1662.

2. Chobanian AV, Bakris GL, Black HR, Cushman WC, Green LA, Izzo JL Jr, Jones DW, Materson BJ, Oparil S, Wright JT Jr, Roccella EJ, National Heart and Blood Institute Joint National Committee on Prevention, and Treatment of High Blood Pressure; National High Blood Pressure Education Program Coordinating Committee: The Seventh Report of the Joint National Committee on Prevention, Detection, Evaluation, and Treatment of High Blood Pressure: the JNC 7 report. JAMA 2003, 289:2560-2572.

3. McGlynn EA, Asch SM, Adams J, Keesey J, Hicks J, DeCristofaro A, Kerr EA: The quality of health care delivered to adults in the United States. $N$ Engl J Med 2003, 348:2635-2645.

4. The ALLHAT Officers and Coordinators for the ALLHAT Collaborative Research Group: Major cardiovascular events in hypertensive patients randomized to doxazosin vs chlorthalidone: the Antihypertensive and Lipid-Lowering Treatment to Prevent Heart Attack Trial (ALLHAT). JAMA 2000, 283:1967-1975.

5. Cabana MD, Rand CS, Powe NR, Wu AW, Wilson MH, Abboud PA, Rubin HR: Why don't physicians follow clinical practice guidelines? A framework for improvement. JAMA 1999, 282:1458-1465.

6. Berwick DM, DeParle NA, Eddy DM, Ellwood PM, Enthoven AC, Halvorson GC, Kizer KW, McGlynn EA, Reinhardt UE, Reischauer RD, Roper WL, Rowe JW, Schaeffer LD, Wennberg JE, Wilensky GR: Paying for performance: Medicare should lead. Health Aff (Millwood) 2003, 22:8-10.

7. Doran T, Fullwood C, Gravelle H, Reeves D, Kontopantelis E, Hiroeh U, Roland M: Pay-for-performance programs in family practices in the United Kingdom. N Engl J Med 2006, 355:375-384.

8. Lindenauer PK, Remus D, Roman S, Rothberg MB, Benjamin EM, Ma A, Bratzler DW: Public reporting and pay for performance in hospital quality improvement. N Engl J Med 2007, 356:486-496.

9. Petersen LA, Woodard LD, Urech T, Daw C, Sookanan S: Does pay-forperformance improve the quality of health care? Ann Intern Med 2006, 145:265-272.

10. Conrad DA, Perry L: Quality-based financial incentives in health care: Can we improve quality by paying for it? Annu Rev Public Health 2009, 30:357-371.

11. Dudley RA: Pay-for-performance research: how to learn what clinicians and policy makers need to know. JAMA 2005, 294:1821-1823.

12. Donner A, Klar N: Design and Analysis of Cluster Randomization Trials in Health Research London: Arnold; 2000

13. Kuhn M: Quality in primary care: economic approaches to analyzing qualityrelated physician behavior London: Office of Health Economics Research; 2003, 92.

14. Bodenheimer $T$, Wagner $E H$, Grumbach $K$ : Improving primary care for patients with chronic illness. JAMA 2002, 288:1775-1779.

15. Bodenheimer T, Wagner $E H$, Grumbach K: Improving primary care for patients with chronic illness: the chronic care model, Part 2. JAMA 2002. 288:1909-1914.

16. Wagner EH, Austin BT, Davis C, Hindmarsh M, Schaefer J, Bonomi A: Improving chronic illness care: translating evidence into action. Health Aff (Millwood) 2001, 20:64-78.

17. Petersen LA, Woodard LD, Henderson LM, Urech TH, Pietz K: Will hypertension performance measures used for pay-for-performance programs penalize those who care for medically complex patients? Circulation 2009, 119:2978-85.

18. Donner A, Klar N: Statistical considerations in the design and analysis of community intervention trials. J Clin Epidemiol 1996, 49:435-439.

19. Lachin JM: Introduction to sample size determination and power analysis for clinical trials. Control Clin Trials 1981, 2:93-113.

20. Kluger AN, DeNisi A: The effects of feedback interventions on performance: a historical review, a meta-analysis, and a preliminary feedback intervention theory. Psychological Bulletin 1996, 119:254-284.

21. Hysong SJ: Meta-analysis: audit and feedback features impact effectiveness on care quality. Med Care 2009, 47:356-363.

22. Cheng J, Edwards $L$, Maldonado-Molina MM, Komro KA, Muller KE: Real longitudinal data analysis for real people: building a good enough mixed model. Stat Med 2010, 29:504-520.

23. Rosamond W, Flegal K, Friday G, Furie K, Go A, Greenlund K, Haase N, Ho M, Howard V, Kissela B, Kittner S, Lloyd-Jones D, McDermott M, Meigs J, Moy C, Nichol G, O'Donnell CJ, Roger V, Rumsfeld J, Sorlie P, Steinberger J, Thom T, Wasserthiel-Smoller S, Hong Y, American Heart Association Statistics Committee and Stroke Statistics Subcommittee: Heart disease and stroke statistics-2007 update: a report from the American Heart Association Statistics Committee and Stroke Statistics Subcommittee. Circulation 2007, 115:e69-171.

24. Grimshaw JM, Thomas RE, MacLennan G, Fraser C, Ramsay CR, Vale L, Whitty P, Eccles MP, Matowe L, Shirran L, Wensing M, Dijkstra R, Donaldson C: Effectiveness and efficiency of guideline dissemination and implementation strategies. Health Technol Assess 2004, 8:iii-iv, 1-72.

25. Epstein $A M$, Lee $T H$, Hamel MB: Paying physicians for high-quality care. $N$ Engl J Med 2004, 350:406-410.

26. Frolich A, Talavera JA, Broadhead P, Dudley RA: A behavioral model of clinician responses to incentives to improve quality. Health Policy 2007, 80:179-193.

27. Petersen $L A$, Urech $T H$, Byrne MM, Pietz $K$ : Do financial incentives in a globally budgeted healthcare payment system produce changes in the way patients are categorized? A five-year study. Am J Manag Care 2007, 13:513-522.

28. Department of Veterans Affairs Health Care Personnel Enhancement Act of 2004. Public Law 108-445 [http://frwebgate.access.gpo.gov/cgi-bin/ getdoc.cgi?dbname=108_cong_public_laws\&docid=f:publ445.108].

doi:10.1186/1748-5908-6-114

Cite this article as: Petersen et al: Design, rationale, and baseline characteristics of a cluster randomized controlled trial of pay for performance for hypertension treatment: study protocol. Implementation Science 2011 6:114.

\section{Submit your next manuscript to BioMed Central and take full advantage of:}

- Convenient online submission

- Thorough peer review

- No space constraints or color figure charges

- Immediate publication on acceptance

- Inclusion in PubMed, CAS, Scopus and Google Scholar

- Research which is freely available for redistribution

Submit your manuscript at www.biomedcentral.com/submit
C Biomed Central 